Proceedings

\title{
Crown-Porphyrin Ligand for Optical Sensors Development ${ }^{\dagger}$
}

\author{
Larisa Lvova 1,* , Elisa Acciari ${ }^{1}$, Federica Mandoj ${ }^{1}$, Giuseppe Pomarico ${ }^{1}$, Corrado Di Natale ${ }^{2}$ and \\ Roberto Paolesse ${ }^{1}$ \\ 1 Department of Chemical Sciences and Technologies, University “Tor Vergata”, 00133 Rome, Italy; \\ elisa.ate@gmail.com (E.A.); federica.mandoj@uniroma2.it (F.M.); pomarico@scienze.uniroma2.it (G.P.); \\ roberto.paolesse@uniroma2.it (R.P.) \\ 2 Department of Electronic Engineering, University “Tor Vergata”, 00133 Rome, Italy; dinatale@uniroma2.it \\ * Correspondence: Larisa.lvova@uniroma2.it; Tel.: +39-06-7269-4755 \\ † Presented at the Eurosensors 2018 Conference, Graz, Austria, 9-12 September 2018.
}

Published: 21 December 2018

\begin{abstract}
A novel porphyrin ligand, Zn(II)TPP-BPI-crown (ZnPC), functionalized with two dibenzo-crown-ether moieties was synthesized and tested as cation-sensitive ionophore. Fluorescence studies on ligand sensitivity towards a number of different metal cations $\left(\mathrm{Na}^{+}, \mathrm{K}^{+}, \mathrm{Li}^{+}\right.$, $\mathrm{Ca}^{2+}, \mathrm{Mg}^{2+}, \mathrm{Co}^{2+}, \mathrm{Cd}^{2+}, \mathrm{Pb}^{2+}, \mathrm{Cu}^{2+}, \mathrm{Zn}^{2+}$ and $\mathrm{NH}_{4}{ }^{+}$) were carried out first in solution and then inside polymeric membrane optodes. Emission light signal was sufficiently brilliant to be captured by a low-cost computer webcam, while a commercial blue-light LED served as monochromic excitation light source. The influence on the $\mathrm{ZnPC}$ optode response of the lipophilic sites functionalization was investigated. The visibly (naked eye) observed color change of sensing material from green to red demonstrated the suitability of the ZnPC-based optodes to perform fast monitoring of $\mathrm{Cu}$ (II) ions in the concentration range between $6.6 \times 10^{-7}$ and $2.4 \times 10^{-2} \mathrm{~mol} / \mathrm{L}$ with a low detection limit (estimated by s/n $=3$ method) of $0.3 \mathrm{mg} / \mathrm{L}$, which is lower than WHO guideline value of $2 \mathrm{mg} / \mathrm{L}$.
\end{abstract}

Keywords: chemical optical sensor; novel Zn(II)-porphyrin ligand functionalized with two dibenzocrown-ether moieties; naked eye detection of $\mathrm{Cu}$ (II) ions

\section{Introduction}

The development of novel sensing materials with analytically useful sensitivity toward metal cations for application in optical chemical sensors is nowadays a challenging task. Ionophores are key components that significantly contribute to the selectivity of polymeric membrane sensors. The use of compounds such as calix[n]arenes, crown-ethers, porphyrins or other ligands containing the cavity of determined size, has permitted previously to develop highly selective electrochemical sensors for cations [1]. On the contrary, less progresses were achieved in the development cationselective optodes, the response of which is dependent on ionophore-analyte interaction and luminescence variation upon complexation [2].

The new ZnPC ligand was synthesized and completely characterized for a first time in the present work for assessment of different metal cations, Figure 1a. In order to enhance cationic selectivity, Zn(II)TPP-BPI porphyrin was functionalized with two dibenzo-crown-ether moieties, which were able to selectively bind the cations of determined size. The fluorescence properties of ZnPC ligand were studied first in solution, then inside PVC-plasticized polymeric membranes. Moreover, the influence of different concentrations of cation-exchanger, potassium tetrakis-(4chlorophenyl)borate (TpCIPBK), on the selective properties of developed optical sensor was investigated. The disposable sensors, both on glass and flexible paper transducers, supplemented 
with familiar devices for signal acquisition (LED as light source and a digital camera as a signal detector), or working on a naked eye mode were developed for fast monitoring of $\mathrm{Cu}$ (II) ions in the wide concentration range.

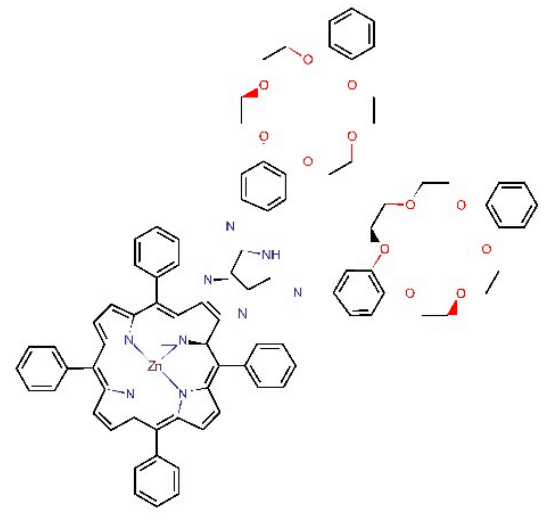

(a)

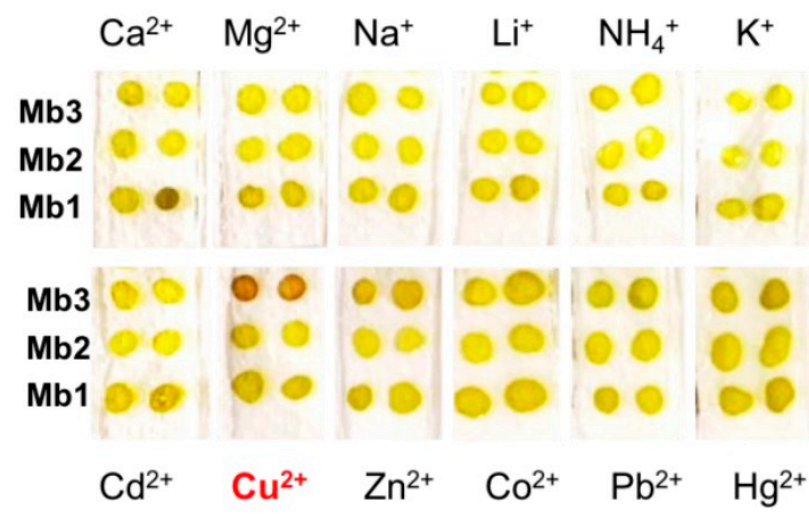

(b)

Figure 1. (a) Chemical structure of tested Zn(II)TPP-BPI-crown ligand, ZnPC; (b) The photograph of optode sensors after testing in different cations solutions in concentration range $6.6 \times 10^{-7}$ to $2.4 \times 10^{-2}$ $\mathrm{mol} / \mathrm{L}$. The measurements were done in 0.01 M HEPES pH 7.4 upon excitation with $380 \mathrm{~nm}$ LED.

\section{Materials and Methods}

Poly(vinyl chloride) (PVC) high molecular weight, tris(2-ethylhexyl) phosphate (TOP), potassium tetrakis-(4-chlorophenyl)borate (TpClPBK), tetrahydrofuran (THF), 4-(2-hydroxyethyl) piperazine-1-ethanesulfonic acid (HEPES), were purchased from Sigma-Aldrich. THF was freshly distilled prior to use. All the other chemicals were of analytical grade and used without further purification. The ligand ZnPC was newly synthesized and characterized in our laboratories.

Polymeric membranes were prepared by incorporation of $1 \mathrm{wt} \%$ of ionophore and $0.5-5 \mathrm{wt} \%$ of TpCIPBK inside a polymeric matrix containing PVC and plasticizer in 1:2 ratio by weight. The membranes of total weight of about $100 \mathrm{mg}$, were dissolved in $1 \mathrm{~mL}$ of THF. $10 \mu \mathrm{L}$ of every membrane cocktail were cast onto transparent glass slides, or paper support; 6 spots were deposited on the same slide, every membrane was replicated twice. THF solvent was allowed to evaporate overnight, afterwords the "disposable" optode sensors were tested in individual solutions $\mathrm{Na}^{+}, \mathrm{K}^{+}, \mathrm{Li}^{+}, \mathrm{Ca}^{2+}$, $\left.\mathrm{Mg}^{2+}, \mathrm{Co}^{2+}, \mathrm{Cd}^{2+}, \mathrm{Pb}^{2+}, \mathrm{Cu}^{2+}, \mathrm{Zn}^{2+}\right)$ and $\mathrm{NH}_{4}^{+}$-ions on 0.01 M HEPES $\mathrm{pH} 7.4$ background in $3.3 \times 10^{-7}-2.4$ $\times 10^{-2} \mathrm{~mol} / \mathrm{L}$ concentration range. The $1 \mathrm{~mol} / \mathrm{L}$ stock solutions of metal salts were prepared dissolving corresponding amounts of metal chlorides and $\mathrm{Pb}$ (II) and $\mathrm{Zn}$ (II) nitrates in distilled water, solutions of lower concentrations were obtained by consecutive additions of calculated amounts of corresponding stock solution.

SHIMAZU RF-1501 fluorimeter was employed for tests in solutions. Blue-colored (380 nm) Light Emitting Diode, LED, was used as light source, and a digital camera as a signal detector for photographic detection of cations. The measurements were performed in a glass or polystyrene (Katrell, model 1937) transparent cells. The responses of the films upon analyte addition were measured with respect to the tree main visible spectrum colors: red, green and blue; obtained RGB signals were evaluated after background luminosity subtraction. The videos captured by camera were transferred into the digital signal and the film optical intensity was plotted versus analyte concentration change.

\section{Results and Discussion}

The enhanced fluorescence of ZnPC ligand in the region $600-750 \mathrm{~nm}$ was due to the $\mathrm{Zn}$ porphyrin optically active unit. Upon the complexation of cation on crown-ether binding sites, the significant fluorescence quenching of $\mathrm{ZnPC}$ was registered and the quenching intensity varied 
depending on analyte nature. The highest fluorescence quenching was registered for alkaline-earth metals, $\mathrm{Mg}(\mathrm{II})$ and $\mathrm{Ca}(\mathrm{II})$, Figure 2A,B.

We have then tested the performance of PVC/TOP membrane optodes containing ZnPC and different amounts of cation-exchanger, TpCIPBK $(0.5,1$ and $5 \mathrm{wt} \%$ respectively) in 0.01 M HEPES background solution $\mathrm{pH}$ 7.4, Table 1.

Table 1. Compositions of tested polymeric membranes, PVC1:plasticizer $=1: 2$.

\begin{tabular}{cccc}
\hline Membrane & Ligand, $\mathbf{m g}$ & Plasticizer & TpClPBK2, $\mathbf{w t} \%$ \\
\hline $\mathrm{Mb} 1$ & ZnPC, 0.9 & TOP3 & 0.5 \\
$\mathrm{Mb} 2$ & ZnPC, 0.7 & TOP & 1 \\
$\mathrm{Mb3}$ & ZnPC, 0.8 & TOP & 5 \\
\hline
\end{tabular}

The highest fluorescence response was recorded for optode with Mb3, doped with $5 \mathrm{wt} \%$ of TpClBPK cation-exchanger. For this sensing material the highest fluorescent response was registered for $\mathrm{Cu}$ (II) ions; moreover, the possibility to perform fast visual monitoring of $\mathrm{Cu}$ (II) ions was demonstrated by the color change of sensing material from green to intensive red, Figure $1 \mathrm{~b}$.

The visibly (naked eye) observed color change of sensing material from green to red, demonstrated the suitability of the $\mathrm{ZnPC}$-based optodes to perform fast monitoring of $\mathrm{Cu}$ (II) ions in the concentration range between $6.6 \times 10^{-7}$ and $2.4 \times 10^{-2} \mathrm{~mol} / \mathrm{L}$ with a low detection limit (estimated by $\mathrm{s} / \mathrm{n}=3$ method) of $0.3 \mathrm{mg} / \mathrm{L}$, which is lower than WHO guideline value of $2 \mathrm{mg} / \mathrm{L}$.
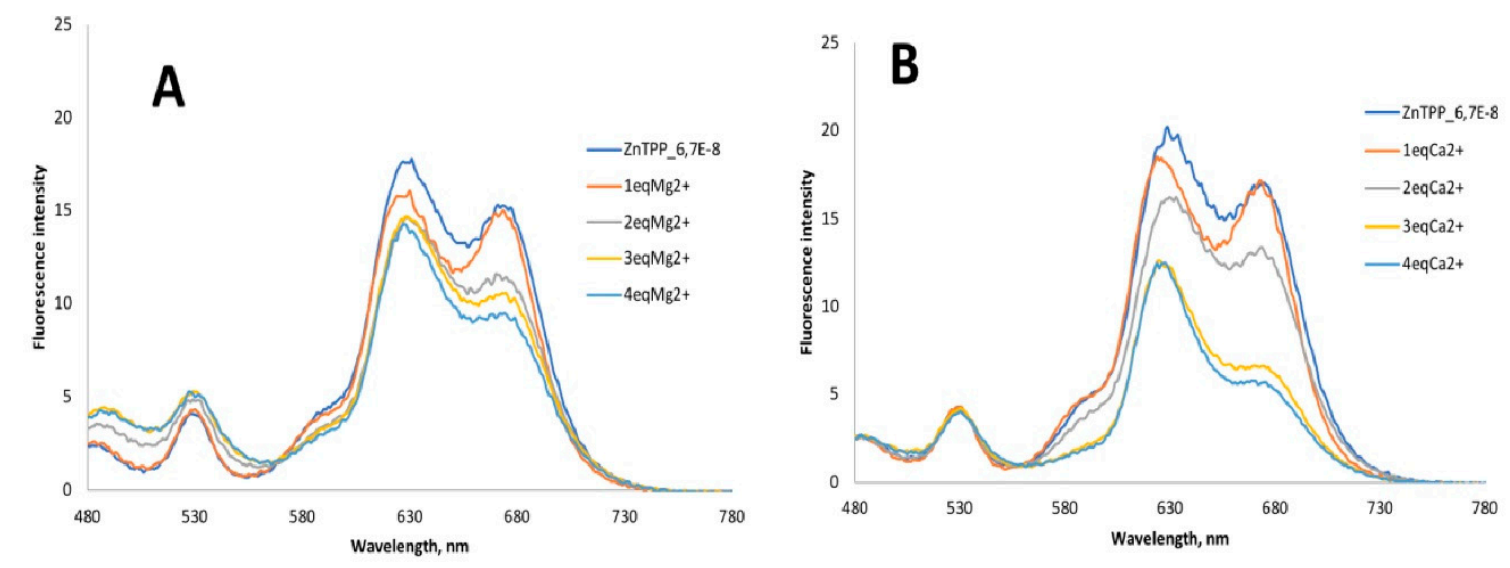

Figure 2. The fluorescence response of $6.7 \times 10^{-8} \mathrm{M} \mathrm{ZnPC}$ in THF upon addition of 1, 2, 3 and 4 equiv. of (A) $\mathrm{Mg}^{2+}$ and (B) $\mathrm{Ca}^{2+}$ ions; $\lambda \mathrm{ex}=460 \mathrm{~nm}$.

Author Contributions: L.L., R.P. and C.D.N. conceived and designed the experiments and wrote the paper; E.A. performed the experiments; F.M. and G.P. designed, synthesized and fully characterized ZnPC ligand.

Conflicts of Interest: The authors declare no conflict of interest.

\section{References}

1. Bakker, E.; Bühlmann, P.; Pretsch, E. Carrier-Based Ion-Selective Electrodes and Bulk Optodes. 2. Ionophores for Potentiometric and Optical Sensors. Chem. Rev. 1998, 98, 1593-1687.

2. Lvova, L.; Goncalves, C.G.; Prodi, L.; Sgarzi, M.; Zaccheroni, N.; Lombardo, M.; Legin, A.; di Natale, C.; Paolesse, R. Systematic approach in Mg2+ ions analysis with a combination of tailored fluorophore design. Anal. Chim. Acta 2017, 988, 96-103.

(C) 2018 by the authors. Licensee MDPI, Basel, Switzerland. This article is an open access article distributed under the terms and conditions of the Creative Commons Attribution (CC BY) license (http://creativecommons.org/licenses/by/4.0/). 